\title{
Football in computer-mediated discourse: \\ A move analysis of match previews*
}

\author{
Mark Nartey (Hong Kong)
}

\begin{abstract}
In the last couple of decades, linguistic enquiry into internet genres has become prevalent, resulting in the investigation of internet genres such as live-text commentary, weblogs, online news/news websites, and social network sites. In tandem with this research tradition, the current study investigated the football match preview in a bid to identify its schematic structure and the rhetorical strategies deployed by producers of this genre in achieving their communicative goal(s). Six match previews taken from two online sports websites, Goal.com and Skysports.com, comprised the data for the study and Swales' (1990; 2004) framework of move analysis was used to analyse the data. The study found that the match preview employed a six-move pattern, namely naming the contest, pre-contest dynamics, predicting team line-ups and team formations, assessing squad strength, discussing the contest and naming the preview author. These moves were found to be realised by a relatively restricted range of lexicogrammatical resources. This study has implications for the construction of the match preview genre and future genre studies.
\end{abstract}

\section{Introduction}

Genre analysis continues to remain a fruitful area of applied linguistic research and has especially been applied to studying language associated with distinct professional and academic communities. To this end, genre theory has been deployed in analysing such genres as the research article (Santos 1996; Anderson/Maclean 1997; Feak/Swales 2009; Ren/Li 2011), dissertation/thesis (Bunton 2002; Hyland 2004; Kwan 2006), inaugural address (Pedersen 2009; Trosborg 2000; Lin 2012), novice/learner writing (Nguyen/Pramoolsook 2014, 2016) and health talk (Sarfo 2011). Genre theory has also been recently applied to language use associated with electronics, in general, and the computer, in particular, resulting in the study of computer based discourses/texts such as the email (Abbasian/Tahririan 2008), the weblog (Herring et al. 2007) and Facebook chatting texts (Sunardi 2015).

This interest in studies on internet genres can be attributed to the growing influence of technology in today's world, stemming from the fact that technology has become quintessential to human existence. Some studies on internet genres (e. g. Pérez-Sabater et al. 2007) have focused on establishing the influence of certain traditional genres like the application letter and the brochure on the development of web genres like direct mail letters, web pages, and the weblog. Other studies (e.g. Herring 2004) have described the features of internet genres as

\footnotetext{
* I am grateful to Elijah Alimsiween Ayaawan for his help and support in the preparation of this paper. Linguistik online 89, 2/18 - http://dx.doi.org/10.13092/lo.89.4274
} 
they actually exist and contrasted that realization of the genre with the ideal form of the genre that is held in the minds of the owners of the genre.

Sports discourse, in general, can be regarded as one of the pervasive discourses enacted on computer-mediated platforms. With particular reference to football computer-mediated discourse, internet genres such as football tweets, online football commentary and pre-and postmatch analysis are prevalent. In recent years, such genres have gained scholarly interest, culminating in some studies in this area. Pérez-Sabater et al. (2007), for instance, investigated football commentary in three different languages (English, French and Spanish) on the 2006 FIFA World Cup and concluded that there is a carryover of the oral features that mark radio and television commentary into the online genre. Georgalou (2009) also examined football commentary in relation to the construction of national identity, arguing that sports journalists may strategically deploy language that seeks to construct a national identity that promotes unification and solidarity amongst their audience. And in a bid to show the nexus between football and war evidenced by the competitive nature of football, Bergh (2011) reported on the use of war terminology and war metaphors in written minute-by-minute match reports.

An important feature of live text commentary that has been investigated is the verbal interaction that occurs in live text commentary as seen in Chovanec's study. The study concluded that the interaction is competitive in nature, "with the commentator always striving to top the reader through humour and criticism" (2006: 1). He also rightly noted that the competitive conflict that marked the interaction was a feature of male discourse. Chovanec (2009), again, explored the live text commentary with a view to unveiling the traces of spoken interaction in the online genre. The study revealed that the live text commentary employed spoken features that created immediacy and a sense of solidarity between and among members of the communicative event.

Like the genre studies on computer-mediated football discourse reviewed above, the present study proposes to examine a relatively under-researched genre within online football discourse - the football match preview. This genre, just like the live text commentary, is a genre that has just about captured the attention of genre scholars, despite its prevalence in computermediated football discourse. Given the paucity of studies on this genre, this study sets out to fill this gap. Specifically, the study seeks to identify the schematic structure and/or organisational pattern of the match preview as well as the distinctive lexico-grammatical resources used in realising the moves. In line with this focus, three research questions are formulated to guide the study:

1. Which moves are used in realising the communicative purpose of the match preview?

2. What is the textual space of each move?

3. Which lexico-grammatical resources are employed in the moves?

\section{Data source and analytical framework}

This study made use of six online previews of English premier league matches played between October and December, 2012. While this sample may be small, the study is still worthwhile in that several "small single-site studies" of genre have emerged in the English for Specific Purposes (ESP) literature and have provided useful insights into various genres and the ability of ESP users (Paltridge 2013: 356). Purposive sampling was used in arriving at the 
sources of the selected previews in order to avoid the potential influence of cultural differences on the realisation of the match preview as a genre. Consequently, all the previews where accessed from online sports websites in the United Kingdom (UK), specifically Goal.com and Skysports.com. The previews were downloaded and converted to Microsoft word format, which served as the work sheet for the analysis. Admittedly, there may be loss of semiotic resources in those previews that came with pictures. However, as the study is not a multimodal discourse analysis, the use of Microsoft word as the work sheet proved suitable.

Given the objective of the study, Swales' (1990; 2004) move analysis approach was adopted. Consequently, "communicative purpose" was used as the principal criterion for the identification of moves. As far as Swales's theory of genre analysis is concerned, the inter-related notions of "discourse community", "genre" and "task" are vital, as they form the bedrock principles on which his genre theory is based. That is, genres are embedded within discourse communities as key properties of these communities and the procedures, actions and events used to process genres may be viewed as tasks. Communicative purpose then becomes the common thread that connects the three notions of community, genre and task. Swales highlights the importance of communicative purpose to his genre theory when he states that "[i]t is communicative purpose that drives the language activities of the discourse community; it is communicative purpose that is the prototypical criterion for genre identity, and it is communicative purpose that operates as the primary determinant of task" (Swales 1990: 10).

Genre scholars (for e. g. Afful 2005; Flowerdew 2015) have averred that the main concern of Swales' genre-base rhetorical approach to the description of text is to identify the rhetorical structure of a genre in relation to its communicative purpose, while paying attention to the social context in which it occurs. The analytical approach of the study was therefore to, first and foremost, identify the moves used in realising the communicative purpose(s) of the match preview subsequent to which the linguistic resources employed in the realisation of such moves are identified. To the extent that the concept of communicative purpose is central to genre-based approaches to language, in general (cf. Miller 1984; Bhatia 1993; Johns 1997), the present study found it useful in the determination of the moves found in the match previews. The textual space allocated to each move was also analysed because that can give an indication of the importance given to the communicative purpose realised by a specific move or step.

Although the study is primarily qualitative in nature, quantitative techniques such as percentages and frequency counts were used to complement the analysis. For the purposes of this study, the definition of a move is taken from Santos who defines a move as "a genre stage which has a particular, minor communicative purpose to fulfil, which in turn serves the major communicative purpose of the genre" (1996: 485). The qualitative approach as used in this study is "primarily an inductive process of organizing data into categories and identifying patterns (relationships) among categories" (McMillan/Schumacher 1993: 479). This makes it possible for an objective detailed description, inductive analysis and interpretation of human behaviour within a social setting (Cresswell 2002; Dawson 2002). The specific qualitative approach used is qualitative content analysis, an approach which, according to Krippendorff (2004), enables researchers to make valid inferences from texts (or other meaningful data) as they relate to their context of usage. 


\section{Discussion and results}

The data revealed a six-move structure of the match preview: introducing the fixture (move 1), team line-ups and team formations (moves 2 and 3), assessing squad strength (move 4), discussing the contest (move 5) and naming the preview author (move 6). This result and the allocated textual space of each move are provided in Table 1. Each of the six moves is subsequently discussed together with the number of steps used in realising the move and the lexicogrammatical resources the move employs. It must be mentioned that although the linguistic resources that typify the moves are discussed simultaneously with the moves, a separate section is used to discuss the verbs of the moves (the hypotactic verb group, in particular) given their relevance to the construction of the match preview.

\begin{tabular}{|c|c|c|c|c|c|c|c|c|c|c|c|c|c|}
\hline \multirow[t]{2}{*}{ Text } & \multicolumn{2}{|c|}{ Move 1: } & \multicolumn{2}{|c|}{ Move 2: } & \multicolumn{2}{|c|}{ Move 3: } & \multicolumn{2}{|c|}{ Move 4: } & \multicolumn{2}{|c|}{ Move 5: } & \multicolumn{2}{|c|}{ Move 6: } & \multirow{2}{*}{$\begin{array}{l}\text { Total } \\
N\end{array}$} \\
\hline & $\mathbf{N}$ & $\%$ & $\mathbf{N}$ & $\%$ & $\mathbf{N}$ & $\%$ & $\mathbf{N}$ & $\%$ & $\mathbf{N}$ & $\%$ & $\mathbf{N}$ & $\%$ & \\
\hline Text 1 & 43 & 9.6 & 26 & 5.8 & 26 & 5.8 & 222 & 49.7 & 127 & 28.5 & 2 & 0.44 & 446 \\
\hline Text 2 & 44 & 13.5 & 26 & 8 & 26 & 8 & 83 & 25.5 & 144 & 44.3 & 2 & 0.6 & 325 \\
\hline Text 3 & 43 & 8.6 & 26 & 5.2 & 26 & 5.2 & 251 & 50.7 & 147 & 29.6 & 2 & 0.4 & 495 \\
\hline Text 4 & 44 & 6.4 & 26 & 3.8 & 26 & 3.8 & 216 & 31.4 & 374 & 54.4 & 2 & 0.3 & 688 \\
\hline Text 5 & 9 & 2.2 & 24 & 5.8 & 24 & 5.8 & 140 & 34.3 & 202 & 49.6 & 8 & 1.9 & 407 \\
\hline Text 6 & 10 & 2.0 & 24 & 4.9 & 24 & 4.9 & 179 & 37.0 & 237 & 49.0 & 9 & 1.8 & 483 \\
\hline Total & 193 & & 152 & & 152 & & 1091 & & 1231 & & 25 & & 2844 \\
\hline
\end{tabular}

Table 1: Moves in the Match Preview and their Textual Space Distribution

\section{Move 1: Introducing the fixture}

From Table 1, it can be inferred that move 1 is a compulsory move, as it can be found in all the six match previews analysed. This move is the move that opens the preview and its communicative purpose, as can be deduced from the name given it, is to introduce the fixture. Two steps are employed in the realisation of this move. Step 1 is naming the contest and step 2 is what I have called pre-contest dynamics. The naming of the contest is done usually with a hyphenated phrase that is constructed with the names of the two football teams involved in the fixture. Below are examples from the data to illustrate this step.

Everton-Sunderland Preview

\section{Manchester united-Arsenal Preview}

The hyphenated phrases above serve the purpose of introducing the fixture by directly naming the teams involved. The second step, pre-contest dynamics, is realised in what can be thought of as a sub-heading in the format of the preview. Its communicative purpose is to inform readers about certain peculiar pre-contest facts that will help them gauge the importance of the contest to either one or both teams. The following is an example from the data. 
Roberto Martinez' team have failed to win in six matches \& face a difficult task against the in-form Londoners, who must overcome with a series of injuries to continue their run.

In terms of textual space, move 1 occupies $9.6 \%$ of the space in text $1 ; 13.5 \%$ in text 2 ; $8.6 \%$ in text $3 ; 6.4 \%$ in text $4 ; 2.2 \%$ in text 5 and $2.0 \%$ in text 6 . For all the six texts, this move places third in terms of textual space in relation to the other five moves. This suggests that as a genre, the match preview does not present too much information in the introduction of the fixture. This is not surprising since it should be expected that an introduction of a match fixture will be concise and straight forward rather than long. The textual space given to this move and the fact that it occurs in all the previews analysed also indicate that it forms an integral part of the preview and, perhaps, may even be considered indispensable to the genre.

\section{Moves 2 and 3: Team line-ups and team formations}

The second and third moves realised in the match preview are team line-ups and team formations. Move 2, team line-ups, has the communicative purpose of informing readers about the probable line-up for each team. This is usually done by naming the individual players that the previewer reckons are the best set to represent each team. Therefore, there are two sets of eleven players arranged according to a certain system in the Goal.com previews. The arrangement of the probable line-ups gives us the predicted formations of the two teams - move 3 . The communicative purpose of move 3 is to give readers basic information about the tactical and technical strategies that the teams are likely to employ. Therefore, moves 2 and 3 are realized simultaneously with respect to word choice. However, the realization of move 3 in the Goal.com previews reflected distinct graphological arrangements which can be viewed as typical of the match preview. This is illustrated below.

\section{EVERTON}

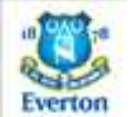

Howard

Coleman, Heitinga, Jagielka, Baines

Pienaar, Osman, Neville, Mirallas

Fellaini

Jelavic
SUNDERLAND

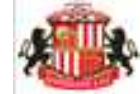

Mignolet

Bardsley, Cuellar, O'Shea, Rose

Johnson, Gardner, Cattermole, McClean

Sessegnon

Fletcher

\section{Figures 1 and 2: Team line-ups and formations (Goal.com)}

In the example above, the writer gives a prediction of the players that will start the contest for the two teams by naming the entire eleven-man squad of both teams. Following from this arrangement, the previewer predicts the formation and/or system of play that the two teams are likely to employ. From the Everton line-up, the predicted formation is thus: four defenders, five midfielders, with one playing as a supporting striker and a main striker (4- 4- 1- 1, graphically speaking). 
As I have already hinted and as can be seen from Table 1, the textual space for moves 2 and 3 is the same in the Goal.com previews: $5.8 \%$ in text 1; $8.0 \%$ in text 2; $5.2 \%$ in text 3 and $3.8 \%$ in text 4 . For the previews taken from Skysports, the textual space for these two moves is $4.9 \%$ for both previews. The same lexical items are used in the realization of both moves with the only difference being the different communicative purposes assigned to them. In comparison with the textual space of the other moves, moves 2 and 3 were allocated the second least space.

It is worth mentioning also that whereas the Goal.com previews used graphology in the realization of these moves, the Skysports previews used a kind of multi-modal technology that allowed the reader to see the pictures of the players that constituted the probable line-up. However, as the present study is not a multimodal analysis, these pictures were not analysed.

\section{Move 4: Assessing squad strength}

This move is the second most important move in the match preview and it occurs in all the previews that served as the data for the study. The communicative purpose of this move is to give readers an update with respect to the "state of affairs" of the playing body. There are two main steps that are used in the realization of this move, viz., injuries and suspensions. Step 1, injuries, was realized in all the previews, therefore having a $100 \%$ rate of occurrence. This step is used to give readers information about players who are not available either due to illhealth or lack of match fitness. The following is an instance from the data.

Roberto Martinez is still without Antolin Alcaraz (groin), so Maynor Figueroa is set to continue on the left of a back three with Jean Beausejour at left wing-back. Albert Crusat (knee) is out, while his fellow winger Ryo Miyaichi (groin) is doubtful.

Step two, suspensions, occurred in 3 of the 6 previews. This step is used by the writer of the preview to inform readers about individuals who are either returning from suspensions or are unavailable for selection due to suspensions. Therefore, it forms part of the previewer's attempt to provide an assessment of the squad by looking at the individuals available for the contest or the personnel available to the manager to pick from. The following example is taken from the data.

Chelsea have both David Luiz and John Terry available for selection after serving their respective one-match and four match bans.

The optional nature of this move is likely to stem from the fact that practically speaking, it is not always the case that there will be issues of suspension for a team. The declarative sentence is one of the linguistic resources used in realizing this move. This sentence is used in the preview to state facts, reinforcing the basic function of the declarative sentence (Quirk/Greenbaum 1973). And the sentences are usually compound and complex in nature. These are respectively exemplified using the sentences below.

1. Roberto Martinez is still without Antolin Alcaraz (groin), so Maynor Figueroa is set to continue on the left of a back three with Jean Beausejour at left wing-back.

2. Albert Crusat (knee) is out, while his fellow winger Ryo Miyaichi (groin) is doubtful. 
The use of these somewhat long sentences in the match preview, I argue, is one of the means of distinguishing the match preview - in terms of lexico-grammatical resources employed from other sister genres such as the live-text commentary, which has been identified by PérezSabater et al. (2008), for instance, to be characterised by short and simple sentences.

\section{Move 5: Discussing the contest}

Move 5, discussing the contest, is the most important move in the match preview. This conclusion is drawn from the textual space allocated to this move. This move has a total word count of 1,231 in the data, which is the highest for all the moves. However, there is some noticeable variation in the textual space allocated to this move across each of the previews. For text 1 , the percentage is $28.5 \%$, second highest for this text; text 2 is $44.3 \%$, which is the highest; text 3 is $29.6 \%$, which is second highest for this text and text 4 is $54.4 \%$, the highest in this text. It has the highest textual space in text 5 and text 6 with $49.6 \%$ and $49.0 \%$ respectively. This variation may stem from the individual writing style of the authors, and also because of the observation made by genre scholars Swales (1990) and Bhatia (1993) that genres tend to be dynamic and allow for innovation and/or variation as is likely to be the case in the present study against the backdrop that the authors of the match preview have different background, experiences and orientations to football analysis.

The communicative purpose of this move is to provide a kind of pre-match (in-depth) analysis of the contest meant to stimulate readers' interest in the contest at hand. It is also a way of situating the contest in proper context because the discussion provides certain clues in respect of the outcome of the contest. There are three steps used in realising this move. Step 1, which I have labelled team form, is used to give a general impression of the team's current level of performance. This step is obligatory and occurs in all the realisations of this move. An example from the data is given below.

Roberto Martinez's side have the joint-worst home record in the league so far with just two draws from their four games, and have conceded two goals in each of their last five Premier League games at the DW Stadium.

The second step used in the realization of this move is the individual form. This step, unlike team form, highlights individuals who are capable of influencing the outcome of the contest. The communicative purpose of this move, therefore, is to introduce readers to these potential game-changers. The following is an example from the data.

Robin van Persie (pictured right) has hit the woodwork 21 times since August 2009; nine more times than any other Premier League player in the same period.

The third step used in the realisation of this move is fixture facts. This step gives a set of hard facts that are supposed to serve as evidence based on which a prediction of the outcome of the game can be made, as shown in the following examples.

The Reds are the only side yet to score a goal in the closing 15 minutes of a league game this season.

Sunderland have not won at Goodison Park since November 1996 when they recorded a 3-1 victory. 
Two functional sentences types are used in the realisation of this move: the interrogative sentence and the simple declarative sentence. For all the previews discussed, the interrogative sentence is one and the same sentence. This interrogative sentence (Did you know?), which appears structurally at the outset of this move, seems to be tied to the website format/design and/or house style. Regarding the declarative sentence, it is the most common way of expressing facts in the English language (Quirk/Greenbaum 1973) - this explains why it is used in the realisation of this move. And this is the only move where a lexical signal is used to express the move. The main lexical signal identified were expressions related to the nickname and stadium of the teams such as the Reds, the Gunners, DW Stadium, Goodison Park, Stadium of Light, etc. One might expect that other lexical means of signalling the move should be found here; however, this was not the case in the present study.

\section{Move 6: Naming the preview author}

Move 6 is the move allocated the least textual space. The total word count for this move is 25 words across the six previews. From text 1 to 6 , the textual space allocated to this move is $0.44 \%, 0.6 \%, 0.4 \%, 0.3 \%, 1.9 \%$ and $1.8 \%$ respectively. This move names the author of the preview, thereby attributing the preview to an identifiable source. It also sometimes provides some contact information about the author. This is especially the case with respect to the previews taken from Skysports. This move is realized simply by a prepositional phrase: for example, by Arthur Virgo and by Husmukh Kerai

From the amount of textual space allocated to this move, it can be concluded that the preview does not provide any information about the author except the name. In fact, apart from the name of the author as in the examples above, no other mention is made of her/him throughout the entire write-up. And this is not alarming given that the focus of any match preview is the match about to be played, of which the previewer is not a key actor.

\section{The hypotactic verb group}

Besides the linguistic resources discussed in relation to each of the moves above, a lexicogrammatical resource that I find worth discussing is the hypotactic verb group. Generally, the verbs that occur across the various moves of the preview can be categorised into two groups: the simple verb phrase and the hypotactic verb group (see Table 2). I only discuss the hypotactic verb group (Halliday/Matthiessen 2004), also known as the serial verb construction, given its centrality to the match preview in suggesting that the match preview is action- or activity-oriented.

The hypotactic verb group as found in the preview is made up of two verb phrases: a primary verb group and a secondary verb group. Its structure comprises a main verb phrase + toinfinitive. The main verb phrase, also considered the primary verb group, is the determinant of tense and agreement of number and person. Examples have been given below.

1. ...is set to continue...

2. ...is expected to continue...

3. ...looks set to retain... 
The semantic relationship between the two groups in the verb phrases above is that of phase (Halliday/Matthiessen 2004). This is because the verbs in the primary group express a general sense of BEING (that is, a state) while the verbs in the secondary group express a sense of DOING (in terms of action). And the verbs in the primary group are elaborated by the verbs in the secondary group. In the examples above, the meaning expressed by the verbs of DOING is that of process. However, there are examples from the data where verbs in the primary group express a mental state or situation which is actualized in the secondary verb group, as demonstrated by the examples below. Table 2 presents the distribution of the verb phrase types across the six moves.

1. ....aim to get back to...

2. ...is expected to continue...

3. ...is projected to win...

\begin{tabular}{|c|c|c|c|c|c|}
\hline \multirow[t]{3}{*}{ Move } & \multicolumn{4}{|c|}{ Verb Phrase Type } & \multirow{3}{*}{$\begin{array}{l}\text { Total } \\
\mathbf{N}\end{array}$} \\
\hline & \multicolumn{2}{|c|}{$\begin{array}{l}\text { Hypotactic Verbal Group } \\
\text { e. g. continues to recover }\end{array}$} & \multicolumn{2}{|c|}{$\begin{array}{l}\text { Simple Verb Phrase } \\
\text { e. g. will play, is filled, has }\end{array}$} & \\
\hline & & $\%$ & & $\%$ & \\
\hline Move 1 & 5 & 41.6 & 7 & 58.3 & 12 \\
\hline Move 2 & 0 & 0 & 0 & 0 & 0 \\
\hline Move 3 & 0 & 0 & 0 & 0 & 0 \\
\hline Move 4 & 14 & 20.5 & 54 & 79.4 & 68 \\
\hline Move 5 & 2 & 2.8 & 67 & 97.1 & 69 \\
\hline Move 6 & 0 & 0 & 0 & 0 & 0 \\
\hline Total & 21 & & 128 & & 149 \\
\hline
\end{tabular}

Table 2: Verb Phrase Type and Distribution across Moves

Table 2 shows that move 1 has the highest percentage (41.6\%) of the hypotactic verb group across the six previews, providing evidence for the importance of the hypotactic verb group to this move. Move 4 also made significant use of the hypotactic verb group, representing $20.5 \%$. The hypotactic verb group also accounted for $2.8 \%$ of the verbs in move 5 . Although their occurrence in these two moves is not as visible as move 1, they are still visible enough to be seen as characteristic of the moves, especially move 4. Moves 2, 3 and 6 are what I will term the verbless moves, as they made no use of verbs. Instead, other linguistic resources such as proper nouns (move 2 e. g. names of the players), graphology (move 3 e.g. the official symbol/crest of the teams) and prepositional phrases (move 6 e. g. by Arthur Virgo) were used. Generally, the hypotactic verb group is used by the previewers to position themselves in relation to the two teams being assessed and to articulate their thoughts, sentiments, opinions, etc. about the teams. Thus, by using these verbs, we get to know what a previewer's (professional) stance on the two teams is as well as his/her (professional) attitude towards them. 


\section{Conclusion}

Drawing on Swales' (1990, 2004) framework of genre analysis, this study explored the match preview genre, focusing on the moves used in the realisation of its overall communicative purpose, the textual space assigned to each move and the lexico-grammatical resources employed. The study revealed that the match preview employs six obligatory moves: naming the fixture, predicting team line-ups, predicting team formations, assessing team strength, discussing the contest, and naming preview author. Hyphenated noun phrases were used in the realization of move 1 while moves 2 and 3 were realized with the same set of linguistic resources. However, graphology was used in the realization of move 3 in the Goal.com previews while multi-modal technology was used in the Skysports previews. Declarative sentences were found to be the main form of expression in move 4 while move 5 employed both declarative and interrogative sentences. Move 6 was realized by prepositional phrases and was allocated the least textual space. Move 5 had the most textual space while moves 2 and 3 shared the same textual space. The hypotactic verb phrase was also found to be an important linguistic resource used in the match preview for expressing previewer stance. Altogether, the findings revealed in this study show that the match preview, like other genres, can be considered as an example of "typified rhetorical action in the context of socially defined recurrent situations" (Yates/Orlikowski 1992: 301). As well, the findings lend credence to the view that a genre is a staged, goal oriented process and a conventionalized communicative event (Swales 1990; Bhatia 1996) and we see from the study that "genres are how things [here, the match preview] get done, when language is used to accomplish them" (Martin 1985: 250).

The six-move schematic structure discovered in this study can serve as a useful guide to sports writers, especially novice writers, in their construction of match previews. The kind of linguistic resources also discovered can be useful for potential sports writers who use the website as their medium of communication. Therefore, the awareness of the conventions of match previews can guide novice writers in their effort to meet the expectations of the discourse community wherein they find themselves. And for expert writers, this awareness may be useful for them if they happen to teach others. These findings, thus, have at least two implications: first, for genre theory, as the current study applies this framework to a relatively under-researched genre. Second, the study has implication for further research. For instance, although the lexico-grammatical resources used in realizing the moves have been discussed in this study, there is no gainsaying the point that further studies must be conducted to establish the array of lexico-grammatical resources that are used in the match preview genre. It should also be desirable for a follow-up study to compare online match previews taken from different websites to help establish whether website design influences the number of moves and the textual space allocated to each move. And a similar study, but with a much larger data will be useful in determining whether the findings herein adduced will be corroborated or repudiated. In sum, this study contributes to genre knowledge by defining and describing the lexical features of the match preview as a genre. 


\section{References}

Abbasian, Fateme/Tahririan, Mohammed Hasan (2008): The discoursal and formal analysis of e-mails: A cross disciplinary genre analysis. Thousand Oaks: Sage.

Afful, Joseph Benjamin (2005): A rhetorical analysis of examination essays in three disciplines: The case of Ghanaian undergraduates. Unpublished $\mathrm{PhD}$ dissertation, National University of Singapore.

Anderson, Kenneth/Maclean, Joan (1997): “A genre analysis of 80 medical abstracts". Edinburgh Working Papers in Applied Linguistics 8: 1-23.

Bergh, Gunnar (2011): Football is war: A case study of minute-by-minute football commentary. Juiz DeFora: Tematica.

Bhatia, Vijay Kumar (1993): Analysing genre: Language use in professional settings. London: Longman.

Bhatia, Vijay Kumar (1996): "Methodological issues in genre analysis". Hermes 16: 39-59.

Bunton, David (2005): "The structure of PhD conclusion chapter". English for Academic Purposes 5/12: 224-226.

Chovanec, Jan (2006): "Competitive verbal interaction in online minute-by-minute match reports". Brno Studies in English 34/1: 23-35.

Chovanec, Jan (2009): "Simulation of spoken interaction in written online media texts". Brno Studies in English 35/2: 109-128.

Creswell, John (2002): Research design: Qualitative, quantitative and mixed methods approaches. Thousand Oaks: Sage.

Dawson, Catherine (2002): Practical research methods: A user-friendly guide to mastering research techniques and projects. Oxford: How to Books.

Feak, Christine/Swales, John (2009): Abstracts and the writing of abstracts. Michigan: Michigan University Press.

Flowerdew, John (2015): “John Swales's approach to pedagogy in genre analysis: A perspective from 25 years on". Journal of English for Academic Purposes 30: 1-11.

Georgalou, Mariza (2009): "Working paper: Scoring a hat trick: Nation, football, and critical discourse analysis". Rice Working Papers in Linguistics 1: 108-141.

Halliday, Michael/Mathiessen, Christian (2004): An introduction to functional Grammar. London: Hodder Education.

Herring, Susan (2007): Computer-mediated discourse. Handbook of discourse analysis. Oxford: Blackwell.

Herring, Susan/Wright, Elijah (2004): "Bridging the gap: A genre analysis of weblogs". In: Herring, Susan (ed.): Computer-mediated communication: Linguistic, social and crosscultural Perspectives. Amsterdam/Philadelphia, Benjamins: 4-18. (= Pragmatics \& Beyond New Series 39).

Hyland, Ken (2004): “Graduates' gratitude: The generic structure of dissertation acknowledgements". English for Specific Purposes 23/3: 209-249.

Johns, Ann (1997): Text, role and context: Developing academic literacies. Cambridge: Cambridge University Press.

Krippendorf, Klaus (2004): Content analysis. An introduction to its methodology. Thousand Oaks: Sage. 
Kwan, Becky (2006): "The schematic structure of literature reviews in doctoral theses of applied Linguistics”. English for Specific Purposes 25/1: 30-55.

Liu, Fang (2012): "Genre analysis of American presidential inaugural speech". Theory and Practice in Language Studies 2/11: 2407-2411.

Martin, James Robert (1985): "Process and text: Two aspects of human semiosis". In: Benson, James/Greaves, William (eds.): Systemic Perspectives on Discourse. Vol. 1. Norwood, Ablex: 248-274.

McMillan, James/Schumacher, Sally (1993): Research in education: A conceptual understanding. New York: Harper Collins.

Miller, Carolyn (1984): “Genre as social action”. Quarterly Journal of Speech 70: 151-167.

Nguyen, Loan/Pramoolsook, Issra (2014): "Rhetorical structure of introduction chapters written by novice Vietnamese TESOL postgraduates". 3L: The Southeast Asian Journal of English Language Studies 20/1: 61-74.

Nguyen, Loan/Pramoolsook, Issra (2016): "Citations in literature review chapters of TESOL master's theses by Vietnamese postgraduates". GEMA Online Journal of Language Studies 16/2: 17-32.

Paltridge, Brian (2013): "Genre and English for specific purposes". In: Paltridge, Brian/Starfield, Sue (eds.): The Handbook of English for Specific Purposes. Chichester, Wiley Blackwell: 347-366.

Pedersen, Michael (2009): An analysis of genre and rhetoric in Barack Obama's inaugural address. Aarhus: Aarhus University Press.

Pérez-Sabater, Carmen et al. (2007): Developing a CMC genre: Online sports broadcasts. Thousand Oaks: Sage.

Pérez-Sabater, Carmen et al. (2008): A spoken genre gets written online football commentaries in English, French, and Spanish. Thousand Oaks: Sage.

Quirk, Randolf/Greenbaum, Sidney (1973): A university grammar of English. Essex: Longman.

Ren, Hongwei/Li, Yuying (2011): “A comparison study on the rhetorical moves of abstracts in published research articles and master's foreign-language theses". English Language Teaching 4/1: 162-166.

Santos, Mauro (1996): "The textual organization of research paper abstracts in applied linguistics". Interdisciplinary Journal for the Study of Discourse 16/4: 481-499.

Sarfo, Emmanuel (2011): "Offering healthcare through radio: An analysis of radio health talk by medical doctors". Journal of Language, Discourse and Society 1/1: 104-125.

Sunardi, Yohana (2015): A genre analysis of Facebook chatting texts. Unpublished B. A. dissertation, Dian Nsuswantoro University.

Swales, John (1990): Genre analysis: English in academic and research settings. Cambridge: Cambridge University Press.

Swales, John (2004): Research genres: Explorations and applications. Cambridge: Cambridge University Press.

Trosborg, Anna (2000): "The inaugural address". In: Trosborg, Anna (ed.): Analysing Professional Genres. Amsterdam, Benjamins: 121-144. 
Yates, Joanne/Orlikowski, Wanda (1992): "Genres of organisational communication: A Structurational approach to studying communication and media". Academy of Management Review 17: 299-326. 